\title{
Current and emerging treatment strategies for vertebral compression fractures
}

\author{
This article was published in the following Dove Press journal: \\ Orthopedic Research and Reviews \\ 27 May 2012 \\ Number of times this article has been viewed
}

\section{Lotfi Hacein-Bey}

Radiological Associates of Sacramento Medical Group Inc, Sacramento, CA, USA
Correspondence: Lotfi Hacein-Bey Radiological Associates of Sacramento Medical Group Inc, I500 Expo Parkway, Sacramento, CA, 958I5, USA

$\mathrm{Tel}+\mathrm{I} 9166468300$

Fax + I 9169204434

Email lhaceinbey@yahoo.com
Background: Vertebral compression fractures are most commonly related to osteoporosis or cancer, both of which are on the rise throughout the world. Once a vertebra is fractured, gradual deterioration of quality of life due to crippling pain and spinal instability usually follows. Although a number of traditional management options have been available to promote pain relief and to allow for increased activities, such as bed rest, bracing, pain medications, and light exercise programs, these have limited effectiveness in the majority of patients. Over 20 years ago, percutaneous vertebroplasty, which is a minimally invasive procedure consisting of the injection of polymethylmethacrylate directly into the fractured vertebra, emerged as an effective treatment. Various vertebral augmentation procedures were subsequently designed, all of which aim at eliminating pain, limiting or reversing vertebral collapse, and providing stability to the affected segment of the spine.

Objective: This article discusses clinical aspects of vertebral compression fractures, current indications and contraindications and summarizes technical aspects of vertebroplasty, kyphoplasty, lordoplasty, and device-implanting vertebral augmentation procedures. Treatment effectiveness, which is significant despite recent criticism of vertebroplasty and other vertebral augmentation procedures, is also discussed. As economic pressures on health care systems are increasing in all countries, it is expected that the appropriateness, clinical effectiveness, and cost-effectiveness of vertebral augmentation procedures will be increasingly established by outcome analyses.

Conclusion: It is important that physicians are familiar with vertebroplasty and other procedures designed to treat vertebral fractures in patients with advanced osteoporosis or cancer. These fractures, which are common and often crippling, had no real effective treatment until the advent of vertebroplasty. The feasibility and effectiveness of vertebral augmentation procedures are high, whereas the complication rates and overall costs are relatively low.

Keywords: vertebral fracture, osteoporosis, vertebroplasty, kyphoplasty, vertebral augmentation

In 1984, Hervé Deramond, a neuroradiologist from Amiens, France, treated a young female patient with a destructive hemangioma of the dens axis causing intractable cervical pain and instability. He used a percutaneous injection of acrylic cement in the vertebra, which resulted in profound, permanent pain relief and improved craniocervical stability. ${ }^{1}$ Soon afterwards, Deramond and colleagues applied the same technique, then dubbed "vertebroplasty," to the treatment of painful, osteoporosis-induced thoracic or lumbar vertebral fractures. ${ }^{2}$ Since then, there has been a worldwide spread in the use of the procedure, which has had a major impact in the past twenty years on the management of vertebral compression fractures of all etiologies. Many patients could now look 
forward to a decent quality of life instead of constant pain and disability. A number of variations in the technique initially described by Deramond have been subsequently designed, all aiming at restoring some degree of height to the treated vertebra, such as kyphoplasty, lordoplasty, and deviceimplanting procedures, all of which appear to provide pain relief rates similar to vertebroplasty, commonly in the $90 \%$ range. The role of technological improvements in the original procedure will continue to be defined as data continue to be collected. Although the appropriateness of vertebroplasty has been recently challenged, over twenty years of strong evidence of its effectiveness speak to its clinical usefulness. Ongoing outcome studies will likely contribute positively to establish further the value of the procedure.

\section{Patient population}

The vast majority of vertebral compression fractures are due to osteoporosis, which is more prevalent than previously thought. In the United States alone, approximately 44 million Americans, representing $55 \%$ of the adult population over the age 50, have either osteoporosis or osteopenia, and many of the 10 million Americans who have osteoporosis are undiagnosed. ${ }^{3}$ Although osteoporosis affects predominantly females in the post-menopausal period, males are affected to almost the same extent, as shown by standards of bone mass measurement.

In addition, vertebral fractures are the most common osteoporosis-related fractures. ${ }^{4}$ Although prevalence estimates are imprecise, partly because of variability in how vertebral fractures are defined, in 2006, approximately 1.4 million patients worldwide but mostly in Europe and the United States were diagnosed with vertebral compression fractures, which cause measurable excess mortality and morbidity. ${ }^{5}$ In the United States alone, of approximately 750,000 vertebral fractures diagnosed each year, only one third receive treatment. ${ }^{6}$ Furthermore, direct care expenditures for osteoporotic fractures in the United States in 2002 were estimated to range from $\$ 12$ billion to $\$ 18$ billion. ${ }^{6}$ Although no single accurate method helps predict which patients are at most risk for fractures, some observations may provide clues. Siminoski et al pointed out that a significant loss in height ( $4 \mathrm{~cm}$ or more) within a short period indicates a higher likelihood of developing a vertebral fracture. ${ }^{7}$

Once an osteoporotic vertebral fracture (Figure 1) has declared itself, there is a significant increase in the load on muscles, ligaments, and facets, which may cause muscle spasm and precipitate facet arthropathy, therefore triggering additional pain-generating mechanisms. In addition, the

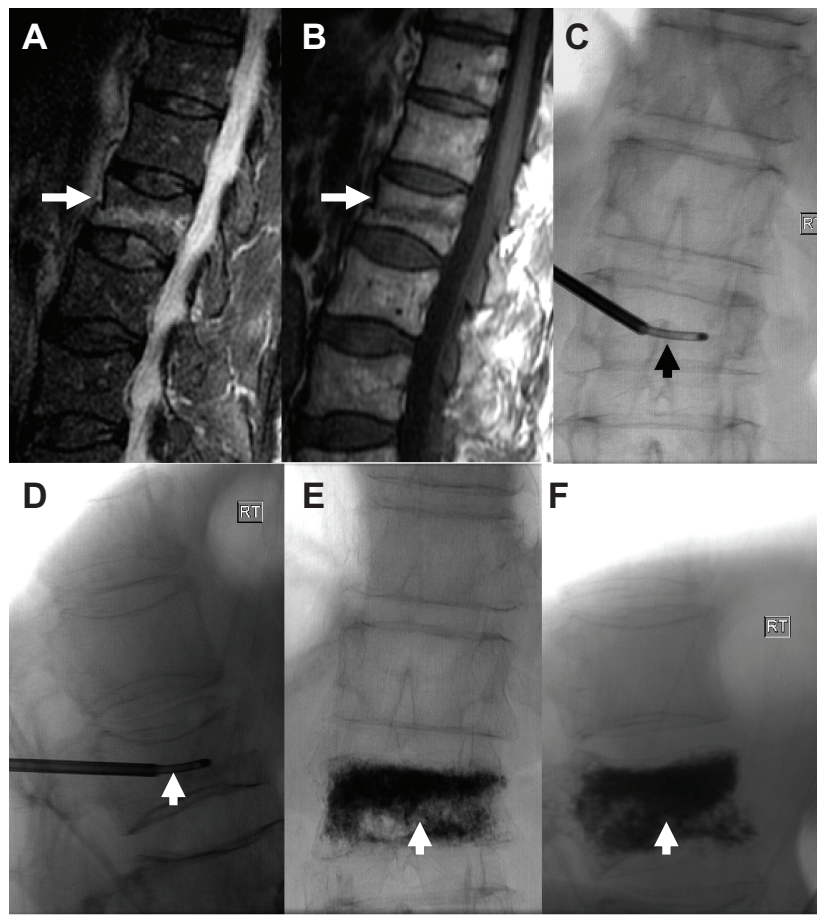

Figure I 7I-year-old female with painful osteoporotic fracture of LI. Edematous cleft within midsection of vertebral body does not fill homogeneously with cement during vertebroplasty. Complete pain relief.

Notes: MRI of the lumbar spine, sagittal TI- (A) and T2-weighted (B) shows cleft of bone marrow edema (arrow) within the midsection of $L I$ vertebral body. (C and D) placement of curved needle (arrow) within the midsection of LI. (E and F) LI vertebral body shows good cement filling, with, however, less homogeneous cement concentration within the area of bone marrow edema (arrow).

center of gravity is displaced forward with angular kyphosis, causing an increased risk for falls and additional axial and appendicular fractures. The progression of kyphotic deformity is another significant source of morbidity because it causes a gradual reduction in lung capacity with a resultant higher risk of pulmonary infections. Severe kyphosis may eventually trigger sternal fractures, which can significantly interfere with breathing and eating, further precipitating the patient's demise.

Neoplastic vertebral fractures are second in prevalence to osteoporosis-related fractures. Metastatic lesions, which typically accelerate osteoclastic activity, increase bone resorption and frequently involve the spinal column. These include breast, lung, and prostate cancers, multiple myeloma (Figure 2), lymphoma, and leukemia. Metastatic vertebral fractures require evaluation not only for their degree of vertebral compression but also for the integrity of the vertebral body posterior wall, epidural and paraspinal extension, presence of associated lesions, and degree of vascularity, all of which may significantly affect prognosis and treatment planning. Advanced destructive lesions may threaten spinal canal integrity and cause neurological deterioration. ${ }^{8}$ Normal 


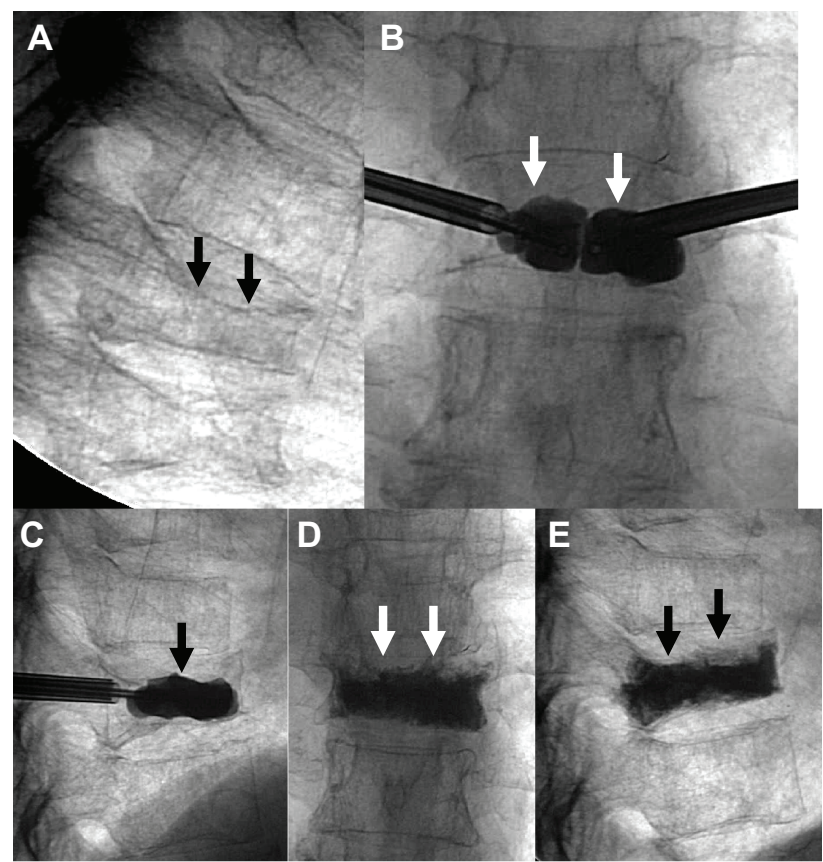

Figure 2 58-year-old female with multiple myeloma and painful TII compression fracture with $50 \%$ height loss. Following kyphoplasty, there is approximately $40 \%$ vertebral height recovery and complete pain relief.

Notes: (A) X-ray of the thoraco-lumbar spine, lateral view, shows a fracture of the superior endplate of TII with about 50\% height loss (arrows). (B) Kyphoplasty, anteroposterior view shows bowing of superior endplate of TII with two balloons (arrows). (C) Kyphoplasty, lateral view shows significant reduction with two balloons (arrows). (D) Thoraco-lumbar spine X-ray, anteroposterior view shows excellent cement filling of TII and height recovery (arrows). (E) Thoraco-lumbar spine X-ray, lateral view, shows excellent cement filling of TII and significant height recovery (arrows).

physiologic loads on the spinal column, such as walking, standing, and sitting may trigger severe bone pain in destructive fractures, which promotes inactivity and a vicious cycle of ensuing increased bone loss. ${ }^{9}$

Although uncommon, vertebral hemangiomas may cause compression fractures. The overwhelming majority are benign, but hemangiomas may become "aggressive" and cause severe pain or compression of the spinal cord or nerve roots, requiring therapy (Figure 3). ${ }^{1,10-12}$

Traumatic vertebral fractures that do not respond to conservative therapy may respond to vertebral augmentation (Figure 4). Currently, there is controversy and significant variability regarding the management of thoracic or lumbar burst fractures. Conservative therapy may result in significant narcotic intake, lack of fracture reduction, and reduced mobility, whereas surgical management has non-negligible risk, including hardware failure. ${ }^{13-16}$ In 2004, Chen and Lee reported on a young patient with work-related burst fractures of three lumbar vertebrae in whom vertebroplasty allowed complete pain relief and stabilization. They further commented on the comparative superiority of percutaneous over operative

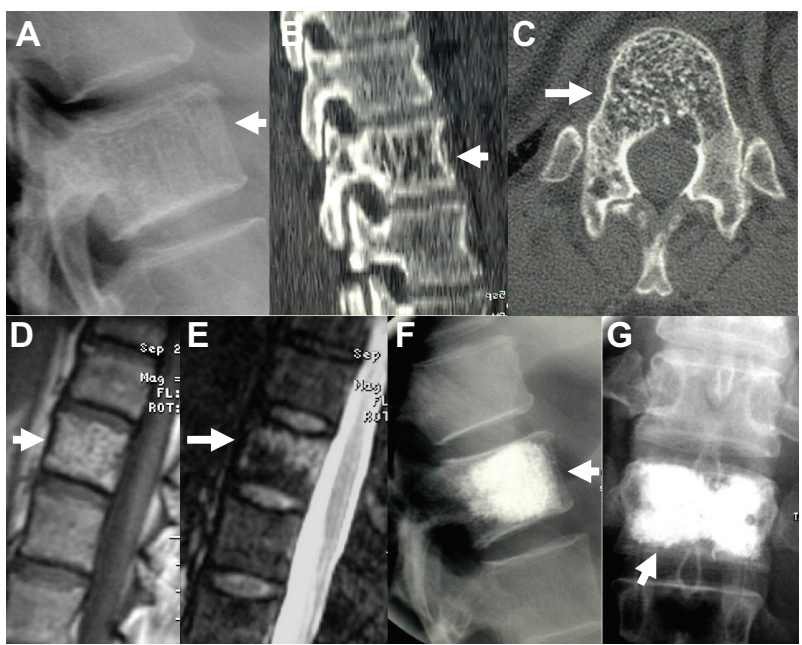

Figure 3 Radiological appearance of painful TI2 vertebral body hemangioma in 48-year-old female. Following vertebroplasty, there is complete pain resolution. Notes: (A) X-ray of the thoraco-lumbar spine, lateral view, shows typical "corduroy" appearance of TI2 vertebra (arrow). (B) CT of thoracic spine, sagittal reconstruction, shows hemangioma (arrow). (C) CT of thoracic spine, axial view at level of TI2, shows hemangioma (arrow). (D) MRI, TI-weighted sagittal view, shows typical TI hyperintense appearance of TI2 vertebral hemangioma (arrow). (E) MRI, T2-weighted sagittal view, shows mixed appearance of TI2 vertebral hemangioma (arrow). (F) Thoraco-lumbar spine X-ray, lateral view, shows excellent cement filling of TI2 after vertebroplasty (arrow). (G) Thoraco-lumbar spine X-ray, anteroposterior view, shows excellent cement filling of TI2 after vertebroplasty (arrow)

intervention, particularly the lack of surgical complications. ${ }^{13}$ In 2005, Amoretti et al reported a series of four patients with burst fractures treated with vertebroplasty, with resultant either complete or significant partial pain relief. ${ }^{14}$ The same year, Acosta et al reported their experience with kyphoplasty and short segment pedicle screw fixation for the treatment of burst fractures of the lumbar spine in five patients. ${ }^{15}$ Extensive clinical and radiological data were obtained in their patients, including measurements of kyphotic angulation, anterior

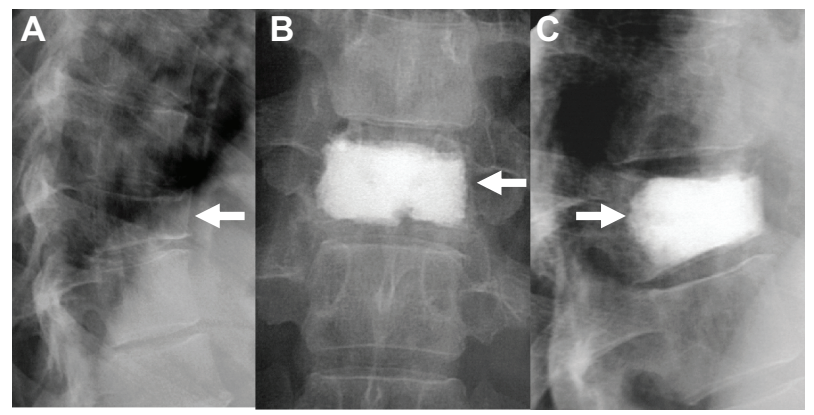

Figure 4 62-year-old female with painful TI2 compression fracture. The patient incurred the fracture at the age of 16 after a fall while horseback riding. Following vertebroplasty, pain that had been constant for 46 years resolved completely.

Notes: (A) X-ray of the thoraco-lumbar spine, lateral view, shows a chronic fracture of the superior endplate of TI2 (arrow). (B) Thoraco-lumbar spine X-ray, anteroposterior view, shows excellent cement filling of TI2 after vertebroplasty (arrow). (C) Thoraco-lumbar spine X-ray, lateral view, shows excellent cement filling of TI2 after vertebroplasty (arrow). 
vertebral body height, and evidence of bone fusion, which supported the authors' conclusion that kyphoplasty may improve the long-term integrity of short-segment pedicle screw constructs and allow for improved rates of fusion and better outcomes in patients with traumatic lumbar burst fractures. ${ }^{15}$

In 2009, Knavel et al reported a large series of traumatic vertebral fractures and concluded that vertebroplasty may be used successfully and safely in instead of more invasive spinal reconstruction techniques. ${ }^{16}$ In 2010, Hartmann et al reported on 26 patients with unstable traumatic lumbar burst fractures (Magerl type A3) treated with kyphoplasty. The patients were extensively assessed pre- and post-operatively both clinically (ie, neurological examination, visual analogue pain scale, Oswestry disability score, and SF-36 functional score) and radiologically (ie, sagittal index, wedge angle, and modified Cobb angle). They concluded that kyphoplasty consistently obtains correction of kyphosis, fracture stabilization, pain reduction, and early mobilization. ${ }^{18}$ Overall, in traumatic fractures, it appears that vertebroplasty and kyphoplasty have very low complication rates (despite a high incidence of asymptomatic cement extravasation), and provide high pain relief rates, significant increases in mobility, and adequate reduction of fractures. ${ }^{13-19}$

\section{Management options, indications and contraindications}

Traditionally, the management of osteoporotic vertebral fractures has relied on bed rest, orthotic bracing, physical therapy, and pain medications. Bed rest and bracing may relieve pain by reducing the compressive loads placed on the vertebral column. However, bed rest increases the risk of complications associated with immobility, and the prolonged use of orthotics can lead to muscular atrophy. Physical therapy aims at strengthening supportive muscles of the abdomen and back, although its early use may actually increase the pain secondary to the instability of the vertebral fracture. Pharmacological therapy of painful fractures includes narcotics, antiepileptics, antidepressants, and muscle relaxants. Each provides specific dampening of the pain response, although all cause sedation, constipation, and gastrointestinal side effects, which are dose-dependent. Patients often choose to use medications over continuing pain, which again leads to immobility.

Neoplastic vertebral fractures are commonly treated with radiation therapy delivered as single-fraction (preferably) or fractionated therapy, which has demonstrated pain relief rates in the $70 \%$ range, although the response is delayed for
2-6 weeks after completion of treatment. Pain relief from radiation is believed to occur from damage to pain receptors and destruction of tumor cells. In many, if not most practices, radiation therapy remains the first line of treatment in metastatic lesions to the spine and is offered in conjunction with adjunct treatment modalities. ${ }^{9,20,21}$ Radiation therapy does not address spinal column instability nor does it reduce the risk of further vertebral collapse. In addition, radiation therapy may compromise bone marrow function, and if performed prior to surgery, promotes wound breakdown and infection, so that surgery should precede radiation therapy if the latter is necessary. ${ }^{9,20,21}$ If there is spinal cord compression, high-dose corticosteroids, and, when indicated, surgical decompression are in order. ${ }^{20}$ Regardless of etiology, vertebral fractures clearly herald a downward course for patients. The pain becomes disabling, altering the patient's quality of life by compromising the ability to perform daily activities, leading to immobility; cognitive function declines through the use of narcotics and muscle relaxants; depression may ensue; pulmonary capacity is reduced; and there is progression of spinal deformity. Variables that should be considered include medical status, projected life expectancy, current pharmaceutical dosing and tolerance, functional capacity, and expectations regarding quality of life as expressed by the patient.

A multidisciplinary approach is essential to ensure proper patient selection and the best possible outcomes. Members of the multidisciplinary team should include the patient, his primary physician, and representatives of various specialties, ideally including palliative care medicine, orthopedic surgery or neurosurgery, interventional (neuro) radiology, hematology oncology, and radiation oncology. Vertebroplasty and other vertebral reconstruction procedures represent a highly effective, minimally invasive therapeutic option for these patients.

Currently accepted indications include painful vertebral compression fractures caused by the following: (1) osteoporosis (primary or secondary), (2) metastatic cancer, (3) multiple myeloma and other hematological neoplastic conditions (ie, lymphoma and leukemia), (4) "aggressive" vertebral hemangiomas, and (5) trauma (particularly when minimal displacement is present and surgery is contraindicated).

There are no absolute contraindications for vertebroplasty or other vertebral augmentation procedures. Relative contraindications include (1) the presence of a systemic infection, and (2) lack of appropriate surgical backup, which could delay treatment. Bleeding conditions are not considered a contraindication, as they can be adequately controlled in the majority of patients prior to the procedure. 


\section{Technical aspects of vertebral augmentation procedures Vertebroplasty}

Vertebroplasty was the first vertebral augmentation procedure described. It is performed by injecting directly bone cement within the spongious bone of the affected vertebral body through needles inserted into both pedicles. The first modification to the technique was to use a unilateral transpedicular approach in order to increase the safety and decrease the duration of the procedure.

Technical improvements subsequently applied to the basic vertebroplasty procedure involved the design of 1) needles, including curved and directional $\left(\mathrm{Cook}^{\circledR}\right.$, Bloomington, IN; DePuy Osseon ${ }^{\circledR}$, Santa Rosa, CA; AvaFlex, CareFusion ${ }^{\circledR}$, San Diego, CA) (Figure 1), and bone filler needles (CareFusion ${ }^{\circledR}$, San Diego, CA; Stryker ${ }^{\circledR}$, Kalamazoo, MI); 2) cavity-creating devices (KyphX Latitude ${ }^{\circledR}$ curette; Medtronic $^{\circledR}$; Minneapolis, MN); and 3) newer cements with higher viscosity, containing bioceramics (Cortoss ${ }^{\circledR}$, Malvern, PA) or calcium phosphate hydroxyapatite (ActivOs $^{\circledR} ;$ Medtronic $^{\circledR}$, Minneapolis, MN). ${ }^{22}$

\section{Lordoplasty}

Lordoplasty was introduced by Orler. ${ }^{23}$ Cannulas are introduced in the fractured and both adjacent vertebrae (above and below), and all treated with cement. The vertebrae above and below the fracture function as internal fixators, allowing the application of a lordotic moment via cannulas to reduce the lordosis while the fractured vertebra is filled with cement. Similar to vertebroplasty, lordoplasty has reported pain relief rates in the $90 \%$ range $^{23}$ and has the theoretical advantage of reducing vertebral and segmental kyphosis by 10-15 degrees.

\section{Kyphoplasty}

Kyphoplasty is based on the concept of inserting and inflating a balloon into a vertebral body to reduce the fracture, thus creating a cavity that is then filled with cement (Figure 2). An orthopedic surgeon, Mark Reiley, and an engineer, Arie Scholten, first developed the technique in the mid-1980s. ${ }^{24}$ The KyphX ${ }^{\circledR}$ Inflatable Bone Tamp ${ }^{\text {TM }}$ (IBT) received 510(k) clearance from the United States Food and Drug Administration (FDA) in July 1998. The device is currently manufactured by Medtronic ${ }^{\circledR}$ (Minneapolis, MN).

Another kyphoplasty device, the Avamax ${ }^{\circledR}$ vertebral balloon (CareFusion, Waukegan, IL), was introduced to the United States market late 2011. It is available in 10, 15 and $20 \mathrm{~mm}$ lengths, similar to the $\mathrm{Kyph}^{\circledR}$ device. This device is marketed specifically for a unilateral approach, as the balloon shaft may be curved, allowing balloon placement in the center of the vertebra.
Vertebral body remodeling devices all differ from vertebroplasty, lordoplasty, and kyphoplasty because they are permanently implanted within the vertebral body, usually in addition to bone cement. Whether implantable devices have greater effectiveness and safety over vertebroplasty and kyphoplasty is not known at this time.

\section{Kiva $^{\text {TM }}$ device}

The Kiva ${ }^{\text {Tw }}$ device (Benvenue Medical Inc, Santa Clara, CA) is a polyether ether ketone (peek) implant (PEEK-OPTIMA ${ }^{\circledR}$ ), which is advanced via a transpedicular approach through a nitinol (nickel titanium) wire, ie, the Kiva wire. This device is currently being investigated in a multicenter trial, the KAST Study (Kiva ${ }^{\text {TM }}$ System as a Vertebral Augmentation Treatment - A Safety and Effectiveness Trial).

\section{The StaXx FX Structural Kyphoplasty System ${ }^{\circledR}$}

The StaXx FX Structural Kyphoplasty System ${ }^{\circledR}$ (Spine Wave, Shelton, CT) is a remodeling device consisting of polyether ether ketone wafers $1 \mathrm{~mm}$ thick. Wafers are inserted one at a time via a percutaneous peripedicular approach and a widebased inserting needle, using a wedge action to create vertical lift and reduce the fractured vertebral body. The first (base) wafer acts as a foundation for subsequently inserted wafers. Once all wafers are inserted, a small volume of bone cement is injected anteriorly at the base of the wafer stack, securing the anterior column for further stabilization.

\section{The Optimesh ${ }^{\circledR}$ device}

The Optimesh $^{\circledR}$ device (Spineology, Saint Paul, MN) is a surgical mesh made of polyethylene terephthalate (PET). The mesh pouch, which contains impacted granular bone graft, is inserted in its empty state through a small cannula and then packed in situ with bone graft within the vertebral body. With increasing amounts of bone graft material packed into the mesh, the OptiMesh ${ }^{\circledR}$ implant is gradually deployed and generates significant distractive force. Once completely filled, the OptiMesh ${ }^{\circledR}$ implant fibers become taut, and granular mechanics transform the contained graft into a custom-fit and rigid load-bearing graft pack. The Optimesh ${ }^{\circledR}$ device is radiolucent and compatible with all imaging modalities.

\section{The VerteLift ${ }^{\text {TM }}$ implant}

The VerteLift ${ }^{\text {TM }}$ implant (SpineAlign Medical Inc, Pleasanton, CA), which is a Nitinol alloy wire, has two basic shapes and a range of sizes. The device acts as an internal scaffold to engage the vertebral body endplates while providing and 
maintaining lift until the bone cement is injected. Prior to cement injection, the VerteLift ${ }^{\mathrm{TM}}$ implant is fully retrievable. The VerteLift ${ }^{\mathrm{TM}}$ implant is currently approved in Europe and undergoing investigational device exemption (IDE) evaluation in the United States.

\section{Patient workup and procedural preparation}

Accurate identification of fractures greatly influences treatment success. Plain radiographs allow the evaluation of bone structure (including posterior vertebral body wall) and quantify height loss when present. However, in both the elderly population and patients with cancer, several fractures of various ages may commonly coexist, hindering identification of symptomatic vertebrae on X-rays alone, even if combined with a reliable clinical examination and fluoroscopy-guided provocative manual palpation. Magnetic resonance imaging (MRI) is the preferred imaging modality, as it allows for dating fractures because it shows bone marrow edema in the early stages of a fracture, which is not present in older fractures (Figure 1). ${ }^{25,26}$ For metastatic spinal lesions, MRI is also very useful as it allows objective and reproducible quantitative assessment of the degree of compression, epidural and paraspinal extension, presence of other lesions, and degree of vascularity. ${ }^{27} \mathrm{MRI}$ was shown to be superior to bone scintigraphy in patients with multiple myeloma. ${ }^{28}$ However, particularly in patients who cannot receive a MRI scan (because of a pacemaker or extreme claustrophobia), bone scintigraphy may accurately identify lesions that may not be detectable on plain X-rays and computed tomography (CT), which identifies increased radiotracer uptake within cortical bone consistent with early inflammatory changes present early in fractures, both osteoporotic and neoplastic. ${ }^{29}$

Vertebral hemangiomas are blood-filled lesions that contain thin-walled, endothelium-lined blood vessels organized in vertically oriented trabeculae surrounded by fatty marrow. Such anatomical arrangement confers to hemangiomas a typical "honeycomb" appearance on plain X-rays, a speckled "polka dot" pattern on CT, and distinctive features on MRI, ie, a bright signal on T1 and T2 weighted images, and significant post-contrast enhancement (Figure 3). ${ }^{30,31}$

At the time of treatment, elderly patients, who have a high incidence of spondylosis, arthritis, and advanced osteoporosis, must be carefully positioned in order to avoid causing new pathology. Supplemental padding of contact points is useful. Suboptimal positioning on the X-ray table and pressure on the ribcage from needle insertion through the pedicles may cause rib fractures relatively easily. Muscle spasm may also be easily triggered or exacerbated by positioning maneuvers. Patients with confusion may be at risk for falling off the fluoroscopic table and therefore should be closely monitored.

Patients on narcotic medications for chronic pain, especially elderly patients, commonly have a higher response threshold to analgesia, requiring larger doses of sedation. Elderly patients may also have significant age-related decreases in renal and hepatic drug clearance, resulting in higher bioavailability of narcotic or other drugs taken at home or administered for a procedure. When midazolam is used for sedation in particular, sudden drops in oxygen saturation may occur, possibly requiring prompt administration of a reversal agent. Adequate patient preparation and education prior to the procedure helps in delivering as little sedation as possible in these patients.

Post procedure patients should be kept in observation for a reasonable amount of time, which should cover a large part of the half-life clearance of drugs used. Even if spectacular pain relief is experienced, patients should remain cautious when initially standing up and walking for a period following the procedure, as the risk of falls persists. The effects of the procedure should be carefully monitored, as ancillary causes of pain may persist in these patients, ie, facet disease, muscle spasm, undiagnosed or new fractures, which may delay patient mobility or require intervention.

\section{Mechanism of pain relief and timing of treatment}

Although the precise mechanism of pain relief from vertebroplasty and other vertebral augmentation procedures has not been fully elucidated, it is generally considered that pain relief is the result of stabilization of microfractures within the vertebral body, particularly at the level of the end plates. ${ }^{32}$ Clinical observations of non-healing, unstable fractures that respond to internal fixation appear to confirm the validity of this mechanism.

Acute fractures that have not undergone bony healing are most likely to respond to reduction and strengthening. Generally, fractures respond to vertebral augmentation within a few weeks of onset. However, chronic non-healing may be observed in very old fractures, which may respond to cement-induced stabilization (Figure 4).

Other less convincing mechanisms have been proposed to explain the positive response to pain from vertebroplasty. Neurolysis from the exothermic reaction that accompanies polymethylmethacrylate polymerization has been suggested as a possible mechanism of pain relief because temperatures reaching $122^{\circ} \mathrm{C}$ have been reported in vitro. ${ }^{33}$ The small doses of cement used in vertebroplasty are however 
unlikely to cause marked temperature elevation, making this an unlikely mechanism. Moreover, although direct chemotoxicity to the pain receptors located within the vertebral body has been proposed, ${ }^{34}$ it has not been confirmed in practice.

\section{Complications}

In the early 1990s, the United States FDA initiated Manufacturer and User Facility Device Experience (MAUDE), a nationwide database designed to record the details of medical complications occurring from the use of medical devices associated with indexed procedures. The earliest reports on vertebroplasty and kyphoplasty were filed in 1999, and the first FDA MAUDE report on complications was published in November 2004. ${ }^{35}$

Of approximately 190,000 procedures, 43 adverse events were reported $(0.02 \%) ; 25 / 43$ events were major, including 4 deaths and 21 instances of spinal cord compression requiring surgery, causing 6 permanent neurologic injuries. ${ }^{35}$ Less severe events included 2 infections ( 1 diskitis, 1 osteomyelitis), 2 pulmonary embolisms, 1 pneumothorax, 3 episodes of blood pressure drop, and 11 technical reports of inconsequential equipment breakage. It was reported that deaths were linked to reactions to the acrylic bone cement, of which the free polymer portion has known cardiotoxicity, ie, cardiac arrhythmias and hemodynamic instability. ${ }^{36}$ This risk is dose dependent, and this complication has been reported only when a large number of vertebrae were treated per session. ${ }^{36}$

Neurologic compromise may result from spinal cord compression because of the leakage of large amounts of cement into the epidural venous plexus, ${ }^{37-39}$ requiring expedited surgical evacuation. ${ }^{37}$ Cement leakage may also cause direct nerve root compression, which can cause new pain or exacerbation of the patient's pain. ${ }^{38}$ Cement leakage in the paravertebral space surrounding the vertebral body or the intervertebral disk may occur in as many as $10 \%$ of procedures and does not usually cause clinical complications. ${ }^{10,40,41}$ However, if injected into the vertebra in a low state of viscosity, cement may migrate back into the spinal canal upon patient mobilization and cause neurological deterioration.

When a posterolateral approach is used instead of a transpedicular approach, there is a risk of pneumothorax at the thoracic level and of psoas hematoma at the lumbar level. ${ }^{42}$ Although the data from the MAUDE study likely underrepresent the actual complication rate from these procedures, which is better reflected in clinical studies, actual overall complication rates from these procedures should be very low, at well under $1 \%$.

\section{Follow-up and risk of new fractures}

Patients should be monitored following vertebral augmentation procedures. Pain may persist despite apparently adequate treatment. Reasons for persistent pain include incomplete treatment of the fractured vertebra, which may respond to a repeat procedure at the same level to obtain a more complete filling with cement. ${ }^{43}$ Pain may result from confounding posterior facet instability and overload resulting from a wedge fracture, which has been identified as a significant cause of residual pain in as many as one third of patients, particularly elderly patients. ${ }^{44}$ However, the most common reason for recurrent or persistent pain following vertebral procedures is another fracture, either new or previously undiagnosed.

The risk of new fractures in vertebrae adjacent to previously treated fractures has been suggested. ${ }^{45,46}$ The risk of postvertebroplasty fractures has been estimated at $12.4 \%$, with $67 \%$ of new fractures present in vertebrae that are immediately adjacent to the initially treated vertebrae, ${ }^{45}$ presumably because reinforced vertebral bodies may alter spine biomechanics. A study on postkyphoplasty reported that $26 \%$ of 40 patients developed a new fracture within 8 months, ${ }^{46}$ and another found an overall incidence of a new fracture of $22.6 \%$ per patient and $15.1 \%$ per kyphoplasty procedure. ${ }^{47}$

However, whether new fractures are caused by augmentation procedures is not currently under consensus. While Grados et al suggested a slight but statistically significant increased risk of vertebral fracture adjacent to cemented vertebrae (odds ratio 1.44; 0.82-2.55), ${ }^{48}$ Jensen and Dion believed that new fractures in adjacent vertebrae following vertebroplasty are related to ongoing osteoporosis. ${ }^{49} \mathrm{~A}$ biomechanical study assessing unconstrained axial compression in spine segments, some healthy, some treated with vertebroplasty, during which shear forces and torque were minimized using a robotic arm, concluded a significant risk of new adjoining vertebral fractures following vertebroplasty owing to the mechanism of endplate deflection. ${ }^{50}$ Conversely, a clinical study of 794 patients equally divided between those treated with vertebroplasty and those with no prior procedure found a similar incidence of new fractures in each group. ${ }^{51}$ Although bone-strengthening, spine-straightening vertebral augmentation procedures may conceptually precipitate new fractures, it is also clear that the diffuse nature of osteoporosis and metastatic cancer increases the likelihood of such occurrences as part of the natural course of the disease by 
virtue of pathologically weakening adjoining vertebrae. Therefore, careful patient follow up and preparedness to treat new fractures are in order.

\section{Clinical effectiveness of vertebroplasty}

Jensen et al of the University of Virginia are credited with the first large scale study to demonstrate the efficacy of vertebroplasty in obtaining pain relief. Published in 1997, their study reported on 29 patients with painful osteoporotic vertebral fractures in whom a $90 \%$ pain relief rate was obtained. ${ }^{52}$ This study played an important role in establishing vertebroplasty in the United States for the treatment of osteoporotic or neoplastic vertebral fractures. In 2000, Barr et al published a retrospective study showing that $95 \%$ of 47 patients treated with vertebroplasty reported pain relief that was at least moderate..$^{53}$ A metaanalysis of retrospective case series and uncontrolled studies reported rates of significant pain relief in the $70 \%-80 \%$ range in patients treated for a variety of osteolytic lesions, including osteoporotic compression fractures, spinal metastases, multiple myeloma, and vertebral hemangiomas. The same study noted that a durable positive response persisted for several months to several years after treatment. ${ }^{54}$ Larger scale metaanalyses later reported pain relief rates for both vertebroplasty and kyphoplasty in the $90 \%$ range..$^{55,56} \operatorname{In} 2002$, McGraw et al reported a series of 100 osteoporotic vertebral fractures treated with vertebroplasty with $97 \%$ significant pain relief at 24 hours of treatment, and $93 \%$ durable relief persisting for at least one year (mean follow up 21.5 months). ${ }^{55}$ Pain relief rates for kyphoplasty were reported in $96.9 \%$ of patients, most occurring within 24 hours. ${ }^{57}$

Regarding neoplastic spinal fractures, in 1996, Weil et al reported the first published series of 37 patients ( 20 men, 17 women; aged 33-86 years) treated with vertebroplasty, $73 \%$ of whom experienced significant pain relief and increased stability, persistent at 6 months. ${ }^{58}$ In 2003, Fourney et al reported on 56 patients with cancer treated with vertebroplasty and kyphoplasty with complete pain relief in $84 \%$, persistent at one year. ${ }^{59}$ Lieberman et al were among the first to evaluate the specific role of kyphoplasty in vertebral fractures caused by cancer and multiple myeloma and to demonstrate favorable rates of vertebral body height restoration, sagittal spinal alignment, and a low risk of cement leakage. ${ }^{60} \mathrm{~A}$ recent large multicenter study of cancer-related vertebral fractures showed superior pain relief and functional scores for kyphoplasty over nonsurgical therapy. ${ }^{61}$

A very interesting retrospective evaluation of some of the earliest patients treated with vertebroplasty by the French group, Deramond et al, ${ }^{1}$ which described the original procedure, ${ }^{2}$ reports the longest follow-up to date in 18 patients treated between 1989 and 1998 with vertebroplasty for vertebral fractures due to osteoporosis $(\mathrm{n}=8)$, hemangiomas $(\mathrm{n}=8)$, and multiple myeloma $(\mathrm{n}=2)$. These patients were re-evaluated clinically and radiologically in 2007 , nearly 20 years after the initial procedure. All patients experienced long-term pain relief, and none demonstrated instability or disc degeneration disproportionate to that demonstrated at adjacent vertebral levels. ${ }^{2}$

Overall, both vertebroplasty and kyphoplasty are credited with similar pain relief rates in the $85 \%-95 \%$ range. .,52-59 $^{-5}$

Kyphoplasty was initially marketed as a treatment of osteoporotic fractures that was superior to vertebroplasty in increasing vertebral body height and reducing angular kyphosis. However, the overall comparative experience shows an average reduction of $4 \mathrm{~mm}$ for kyphoplasty versus $2.2 \mathrm{~mm}$ for vertebroplasty. ${ }^{35}$ There is currently no indication whether the overall minimal difference in reduction is clinically significant. Another alleged advantage of kyphoplasty is to allow for "lower pressure" cement injections because a cavity is initially created in the vertebral body by the balloon tamp, instead of injecting a "thinner" mixture as a forced intramedullary perfusate. Although it is suggested that more cement leaks occur with vertebroplasty than with kyphoplasty ${ }^{35}$ an experimental study noted higher injection pressures with the use of larger systems within voids created by bone tamps. ${ }^{62}$

In all device-implanting vertebral augmentation procedures, pain relief rates appear to be within the range of those currently obtained with vertebroplasty and kyphoplasty. However, no data on large-scale outcomes are currently available.

Two highly publicized critical reports in the form of randomized controlled trials, both published in the same 2009 issue of the New England Journal of Medicine (NEJM), challenged the efficacy of vertebroplasty in obtaining pain relief. ${ }^{63,64}$ In both studies, patients with vertebral fractures were randomly treated with either vertebroplasty or a simulated procedure, ie, placement of a needle alone in the vertebra. ${ }^{63,64}$ Both studies generated significant concern regarding their conduct and conclusions. First, ethical concerns were expressed about offering sham or simulated procedures to patients in severe pain. ${ }^{63-68}$ Second, patients in the treated arm received minimal amounts of cement, much lower than clinically useful volumes capable of restoring vertebral body structure and providing pain relief. ${ }^{65}$ Third, mean treatment timing was beyond the clinically useful time window for most patients (12 months versus 8 weeks) ${ }^{66}$ Fourth, in both studies, patients treated were outpatients, whereas most ver- 
tebral augmentation procedures are performed on inpatients. Further, it has been argued that leaving those patients at home would expose them to complications of prolonged bed rest and narcotic analgesia. ${ }^{67}$ Finally, and most important, concerns about the adequacy of the treatment effect evaluation were expressed. ${ }^{68}$ Although a $30 \%$ decrease in pain at one month was arbitrarily considered clinically meaningful, the statistics used did not allow the observed effect to be taken into account. Both studies used a "responder analysis" approach, but neither study was able to detect differences in response adequately. ${ }^{68}$

Soon after the publication of the two NEJM studies, the results of the large vertebroplasty versus conservative treatment in acute osteoporotic vertebral compression fractures (VERTOS) II trial were made public. ${ }^{69}$ VERTOS, a prospective randomized trial of vertebroplasty and conservative treatment in 202 patients, showed that vertebroplasty resulted in greater pain relief than conservative treatment with a significant difference in mean visual analog scale (VAS) scores between baseline and one month. The VERTOS study concluded that in a subgroup of patients with acute osteoporotic vertebral compression fractures and persistent pain, percutaneous vertebroplasty is both effective and safe, providing pain relief that is immediate, sustained for at least one year, and at an acceptable cost, which significantly exceeds the relief achieved with conservative treatment.

\section{Future directions}

As economic pressures are mounting on health care in all countries, the performance of outcome analyses will continue, which will likely establish further the appropriateness, clinical effectiveness, and cost-effectiveness of vertebral augmentation. However, despite low procedural risk and several decades of experience with the use of acrylic cements for bone augmentation, a prophylactic role for vertebral augmentation remains unlikely at this time. New cements are currently being investigated, with a focus on improving viscosity and polymerization times, ${ }^{70}$ including mineral bone cements, hydroxyapatite cements, osteoconductive materials (coral exoskeleton and calcium materials) and morphogenic proteins. ${ }^{71}$ Image-guided minimally invasive technology combining robotics and stereotactic guidance is also an area of active investigation and is expected to generate safer automated treatment approaches in the future..$^{72,73}$

\section{Conclusion}

Significant evidence supports the role of vertebroplasty and kyphoplasty in adequately selected patients with vertebral fractures caused by advanced osteoporosis, cancer, hemangiomas, or trauma. Vertebral augmentation will continue to make positive contributions to the lives of numerous patients in the form of measurable improvements in quality of life and survival rates. Whether newer, device-implanting vertebral augmentation procedures will translate into greater safety and effectiveness has yet to be established.

\section{Disclosure}

The author reports no conflicts of interest in this work.

\section{References}

1. Galibert P, Deramond H, Rosat P, Le Gars D. Preliminary note on the treatment of vertebral angioma by percutaneous acrylic vertebroplasty. Neurochirurgie. 1987;33:166-168. French.

2. Franc J, Lehmann P, Saliou G, et al. Vertebroplasty: 10 years clinical and radiological follow-up. J Neuroradiol. 2010;37(4):211-219.

3. US Department of Health and Human Services. Bone health and osteoporosis: a report of the surgeon general. US Department of Health and Human Services, Office of the Surgeon General; 2005.

4. National Osteoporosis Foundation. Fast facts on osteoporosis. National Osteoporosis Foundation; 2005. Available from: http://www.nof.org/. Accessed March 28, 2005

5. Johnell O, Kanis JA. An estimate of the worldwide prevalence and disability associated with osteoporotic fractures. Osteoporos Int. 2006;17(12):1726-1733.

6. Weinstein JN. Balancing science and informed choice in decisions about vertebroplasty. N Engl J Med. 2009;361:619-621.

7. Siminoski K, Jiang G, Adachi JD, et al. Accuracy of height loss during prospective monitoring for detection of incident vertebral fractures. Osteoporos Int. 2005;16(4):403-410.

8. Sundaresan N, Galicich JH, Lane JM, Bains MS, McCormack P. Treatment of neoplastic epidural cord compression by vertebral body resection and stabilization. J Neurosurg. 1985;63:676-684.

9. Shepherd S. Radiotherapy and the management of metastatic bone pain Clin Radiol. 1988;39:547-550.

10. Depriester C, Deramond H, Toussaint P, Jhaveri HS, Galibert P. Percutaneous vertebroplasty: indications, technique and complications. In: Connors JJ III, Wojak JC, editors. Interventional Neuroradiology, Strategies and Practical Techniques. Philadelphia, PA: Saunders; 1999: 346-357.

11. Deramond H, Depriester C, Galibert P, Le Gars D. Percutaneous vertebroplasty with polymethylmethacrylate: technique, indications, and results. Radiol Clin North Am. 1998;36:533-546.

12. Brunot S, Berge J, Barreau X, Ménégon P, Dousset V. Long term clinical follow up of vertebral hemangiomas treated by percutaneous vertebroplasty [in French]. J Radiol. January 2005;86(1):41-47.

13. Chen J, Lee S. Percutaneous vertebroplasty for the treatment of thoracolumbar spine bursting fractures. $J$ Neurosurg Spine. 2004;1: 228-231.

14. Amoretti N, Hovorka E, Marcy P, et al. Burst fracture of the spine involving vertebrae presenting no other lesions: the role of vertebroplasty. Clin Imaging. 2005;29:379-382.

15. Acosta FL Jr, Aryan HE, Taylor WR, Ames CP. Kyphoplasty-augmented short-segment pedicle screw fixation of traumatic lumbar burst fractures: initial clinical experience and literature review. Neurosurg Focus. 2005;18(3):e9.

16. Knavel EM, Thielen KR, Kallmes DF. Vertebroplasty for the treatment of traumatic nonosteoporotic compression fractures. AJNR Am J Neuroradiol. 2009;30(2):323-327.

17. Costa F, Ortolina A, Cardia A, et al. Efficacy of treatment with percutaneous vertebroplasty and kyphoplasty for traumatic fracture of thoracolumbar junction. J Neurosurg Sci. 2009;53(1):13-17. 
18. Hartmann F, Gercek E, Leiner L, Rommens PM. Kyphoplasty as an alternative treatment of traumatic thoracolumbar burst fractures Magerl type A3. Injury. 2012;43(4):409-415.

19. Stadhouder A, Buskens E, de Klerk LW, et al. Traumatic thoracic and lumbar spinal fractures: operative or nonoperative treatment: comparison of two treatment strategies by means of surgeon equipoise. Spine. 2008;33:1006-1017.

20. Dy SM, Asch SM, Naeim A, Sanati H, Walling A, Lorenz KA. Evidence-based standards for cancer pain management. J Clin Oncol. 2008;26(23):3879-3885.

21. Haley M, Gerszten PC. Stereotactic radiosurgery in the management of cancer pain. Curr Pain Headache Rep. 2009;13(4):277-281.

22. Ortiz O, Mathis JM. Vertebral body reconstruction: techniques and tools. Neuroimaging Clin N Am. 2010;20(2):145-158.

23. Orler R, Frauchiger LH, Lange U, Heini PF. Lordoplasty: report on early results with a new technique for the treatment of vertebral compression fractures to restore the lordosis. Eur Spine J. 2006;15(12): 1769-1775.

24. Hacein-Bey L, Guermazi A. Percutaneous kyphoplasty in vertebral compression fractures. In: Gangi A, Guth S, Guermazi A, editors. Imaging in Percutaneous Musculoskeletal Interventions Medical Radiology Series, Springer-Verlag Berlin Heidelberg; 2009:259-281.

25. Do HM. Magnetic resonance imaging in the evaluation of patients for percutaneous vertebroplasty. Top Magn Reson Imaging. 2000;11: 235-244.

26. Lindsay R, Silverman SL, Cooper C. Risk of new vertebral fracture in the year following a fracture. JAMA. 2001;285:320-323.

27. Georgy BA. Metastatic spinal lesions: state-of-the-art treatment options and future trends. AJNR Am J Neuroradiol. 2008;29(9):1605-1611.

28. Masala S, Schillaci O, Massari F, et al. MRI and bone scan imaging in the preoperative evaluation of painful vertebral fractures treated with vertebroplasty and kyphoplasty. In Vivo. 2005;19:1055-1060.

29. Maynard AS, Jensen ME, Schweickert PA, Marx WF, Short JG, Kallmes DF. Value of bone scan imaging in predicting pain relief from percutaneous vertebroplasty in osteoporotic vertebral fractures. AJNR Am J Neuroradiol. 2000;21:1807-1812.

30. Friedman DP. Symptomatic vertebral hemangiomas: MR findings. $A J R$ Am J Roentgenol. 1996;167:359-364.

31. Jones JO, Bruel BM, Vattam SR. Management of painful vertebral hemangiomas with kyphoplasty: a report of two cases and a literature review. Pain Physician. 2009;12(4):E297-E303.

32. Belkoff SM, Maroney M, Fenton DC, Mathis JM. An in vitro biomechanical evaluation of bone cements used in percutaneous vertebroplasty. Bone. 1999;25(Suppl 2):23S-26S.

33. Jefferiss CD, Lee AJ, Ling RS. Thermal aspects of self curing polymethylmethacrylate. J Bone Joint Surg Br. 1975;57:511-518.

34. Seppalainen AM, Rajaniemi R. Local neurotoxicity of methyl methacrylate among dental technicians. Am J Ind Med. 1984;5:471-477.

35. Nussbaum DA, Gailloud P, Murphy K. A review of complications associated with vertebroplasty and kyphoplasty as reported to the food and drug administration medical device related web site. J Vasc Interv Radiol. 2004;15:1185-1192.

36. Kaufmann TJ, Jensen ME, Ford G, Gill LL, Marx WF, Kallmes DF. Cardiovascular effects of polymethylmethacrylate use in percutaneous vertebroplasty. AJNR Am J Neuroradiol. 2002;23:601-604.

37. Shapiro S, Abel T, Purvines S. Surgical removal of epidural and intradural polymethylmethacrylate extravasation complicating percutaneous vertebroplasty for an osteoporotic lumbar compression fracture: case report. J Neurosurg. 2003;98(Suppl 1):90-92.

38. Lee BJ, Lee SR, Yoo TY. Paraplegia as a complication of percutaneous vertebroplasty with polymethylmethacrylate: a case report. Spine. 2002;27:E419-E422.

39. Harrington KD. Major neurological complications following percutaneous vertebroplasty with polymethylmethacrylate: a case report. J Bone Joint Surg Am. 2001;83-A:1070-1073.
40. Coumans JV, Reinhardt MK, Lieberman IH. Kyphoplasty for vertebral compression fractures: 1-year clinical outcomes from a prospective study. J Neurosurg Spine. 2003;99:44-50.

41. Mathis JM, Barr JD, Belkoff SM, Barr MS, Jensen ME, Deramond H. Percutaneous vertebroplasty: A developing standard of care for vertebral compression fractures. AJNR Am J Neuroradiol. 2001;22:373-381.

42. Laredo JD, Bellaiche L, Hamze B, Naouri JF, Bondeville JM, Tubiana JM. Current status of musculoskeletal interventional radiology. Radiol Clin North Am. 1994;32:377-398.

43. Kim HW, Kwon A, Lee MC, Song JW, Kim SK, Kim IH. The retrial of percutaneous vertebroplasty for the treatment of vertebral compression fracture. J Korean Neurosurg Soc. 2010;47(4):278-281.

44. Wilson DJ, Owen S, Corkill RA. Facet joint injections as a means of reducing the need for vertebroplasty in insufficiency fractures of the spine. Eur Radiol. 2011;21(8):1772-1778.

45. Uppin AA, Hirsch JA, Centenera LV, Pfiefer BA, Pazianos AG, Choi IS. Occurrence of new vertebral body fracture after percutaneous vertebroplasty in patients with osteoporosis. Radiology. 2003;226: 119-124.

46. Fribourg D, Tang C, Sra P, Delamarter R, Bae H. Incidence of subsequent vertebral fracture after kyphoplasty. Spine. 2004;29: 2270-2276.

47. Harrop JS, Prpa B, Reinhardt MK, Lieberman I. Primary and secondary osteoporosis: incidence of subsequent vertebral compression fractures after kyphoplasty. Spine. 2004;29:2120-2125.

48. Grados F, Depriester C, Cayrolle G, Hardy N, Deramond H, Fardellone P. Long-term observations of vertebral osteoporotic fractures treated by percutaneous vertebroplasty. Rheumatology (Oxford). 2000;39(12): $1410-1414$.

49. Jensen ME, Dion JE. Percutaneous vertebroplasty in the treatment of osteoporotic compression fractures. Neuroimaging Clin $\mathrm{N} \mathrm{Am}$. 2000;10(3):547-568.

50. Fahim DK, Sun K, Tawackoli W, et al. Premature adjacent vertebral fracture after vertebroplasty: a biomechanical study. Neurosurgery. 2011;69(3):733-744.

51. Chosa K, Naito A, Awai K. Newly developed compression fractures after percutaneous vertebroplasty: comparison with conservative treatment. Jpn J Radiol. 2011;29(5):335-341.

52. Jensen ME, Evans AJ, Mathis JM, Kallmes DF, Cloft HJ, Dion JE. Percutaneous polymethylmethacrylate vertebroplasty in the treatment of osteoporotic vertebral body compression fractures: technical aspects. AJNR Am J Neuroradiol. 1997;18:1897-1904.

53. Barr JD, Barr MS, Lemley TJ, McCann RM. Percutaneous vertebroplasty for pain relief and spinal stabilization. Spine. 2000;15(25):923-928.

54. Levine SA, Perin LA, Hayes D, Hayes WS. An evidence-based evaluation of percutaneous vertebroplasty. Manag Care. 2000;9: $56-60$.

55. McGraw JK, Lippert JA, Minkus KD, Rami PM, Davis TM, Budzik RF. Prospective evaluation of pain relief in 100 patients undergoing percutaneous vertebroplasty: results and follow-up. J Vasc Interv Radiol. 2002;13(9 Pt 1):883-886.

56. Heini PF, Walchli B, Berlemann U. Percutaneous transpedicular vertebroplasty with PMMA: operative technique and early results: a prospective study for the treatment of osteoporotic compression fractures. Eur Spine J. 2000;9:445-450.

57. Lane JM, Girardi F, Parvataneni HK, et al. Preliminary outcomes of the first 226 consecutive kyphoplasties for the fixation of painful osteoporotic vertebral compression fractures [abstract]. Osteoporosis Int. 2000;11(Suppl 2):206.

58. Weill A, Chiras J, Simon JM, Rose M, Sola-Martinez T, Enkaoua E. Spinal metastases: indications for and results of percutaneous injection of acrylic surgical cement. Radiology. 1996;199:241-247.

59. Fourney DR, Schomer DF, Nader R, et al. Percutaneous vertebroplasty and kyphoplasty for painful vertebral body fractures in cancer patients. J Neurosurg Spine. 2003;98:21-30. 
60. Lieberman I, Reinhardt MK. Vertebroplasty and kyphoplasty for osteolytic vertebral collapse. Clin Orthop Relat Res. 2003; (Suppl 415):S176-S186.

61. Berenson J, Pflugmacher R, Jarzem P, et al. Cancer Patient Fracture Evaluation (CAFE) Investigators. Balloon kyphoplasty versus nonsurgical fracture management for treatment of painful vertebral body compression fractures in patients with cancer: a multicentre, randomised controlled trial. Lancet Oncol. 2011;12(3):225-235.

62. Agris JM, Zoarski GH, Stallmeyer MJB, Ortiz O. Intravertebral pressure during vertebroplasty: a study comparing multiple delivery systems. Presented at the annual meeting of the American Society of Spine Radiology, Scottsdale, AZ, February 19-23, 2003.

63. Kallmes DF, Comstock BA, Heagerty PJ, et al. A randomized trial of vertebroplasty for osteoporotic spinal fractures. $N$ Engl J Med. 2009;361:569-579.

64. Buchbinder R, Osborne RH, Ebeling PR, et al. A randomized trial of vertebroplasty for painful osteoporotic vertebral fractures. $N$ Engl $J$ Med. 2009;361:557-568.

65. Noonan P. Randomized vertebroplasty trials: bad news or sham news? AJNR Am J Neuroradiol. 2009;30(10):1808-1809.

66. Gangi A, Clark WA. Have recent vertebroplasty trials changed the indications for vertebroplasty? Cardiovasc Intervent Radiol. 2010; 33(4):677-680.
67. Wagner AL. Vertebroplasty and the randomized study: where science and ethics collide. AJNR Am J Neuroradiol. 2005;26(7):1610-1611.

68. Georgy B. Can meta-analysis save vertebroplasty? AJNR Am J Neuroradiol. 2011;32(4):614-616.

69. Klazen CA, Lohle PN, de Vries J, et al. Vertebroplasty versus conservative treatment in acute osteoporotic vertebral compression fractures (VERTOS II): an open-label randomised trial. Lancet. 2010;376:1085-1092.

70. Kolk A, Handschel J, Drescher W, et al. Current trends and future perspectives of bone substitute materials: from space holders to innovative biomaterials Epub 2012 Jan 30. J Craniomaxillofac Surg.

71. Kwon B, Jenis LG. Carrier materials for spinal fusion. Spine J. 2005;5(Suppl 6):224S-230S.

72. Cleary K, Clifford M, Stoianovici D, Freedman M, Mun SK, Watson V. Technology improvements for image-guided and minimally invasive spine procedures. IEEE Trans Inf Technol Biomed. 2002;6(4): $249-261$.

73. Kantelhardt SR, Martinez R, Baerwinkel S, Burger R, Giese A, Rohde V. Perioperative course and accuracy of screw positioning in conventional, open robotic-guided and percutaneous robotic-guided, pedicle screw placement. Eur Spine J. 2011;20(6):860-868.
Orthopedic Research and Reviews

\section{Publish your work in this journal}

Orthopedic Research and Reviews is an international, peer-reviewed, open access journal focusing on the patho-physiology of the musculoskeletal system, trauma, surgery and other corrective interventions to restore mobility and function. Advances in new technologies, materials, techniques and pharmacological agents are particularly welcome. The journal welcomes

\section{Dovepress}

original research, clinical studies, reviews \& evaluations, expert opinion and commentary, case reports and extended reports. The manuscript management system is completely online and includes a very quick and fair peer-review system, which is all easy to use. Visit http://www.dovepress. com/testimonials.php to read real quotes from published authors. 